\title{
Migración, una epistemología ausente Aproximación teológico fundamental
}

\author{
Luis MAUricio AlbornOz Olivares* \\ Universidad Católica del Maule (Chile) \\ albornoz@ucm.cl
}

\begin{abstract}
Resumen
La movilidad humana es un fenómeno social que ha puesto en la sensibilidad pública nacional una serie de iquietudes, que han derivado en definciones normativas desde la política pública. Tras decisiones de orden administrativo, emergen convicciones sociales y culturales que tienden a relativizar, y en otros casos estigmatizar ciertas realidades migratorias subjetivamente evaluadas. En este contexto el aporte que podemos reconocer desde una reflexión teológica, contribuye a ampliar la mirada y reorientar aquellas conviciones previas que se ven iluminadas desde otra epistemología. El presente artículo busca poner el desafío de acoger la movilidad humana en perspectiva teológico fundamental y reconocer allí la integración de un fenómeno que interpela hoy nuestra realidad nacional.
\end{abstract}

Palabras clave: migración, teología, movilidad, cristianismo, epistemología.

\section{Migration, an absent epistemology \\ Fundamental theological approach}

\begin{abstract}
Human mobility is a social phenomenon that has put a series of concerns in the national public sensibility, which have resulted in normative definitions from public policy. After administrative decisions, social and cultural convictions emerge that tend to relativize, and in other cases stigmatize certain subjectively evaluated migration realities. In this context, the contribution that we can recognize from a theological reflection, helps to broaden the look and redirect those previous convictions that are illuminated from another epistemology. This article seeks to put the challenge of welcoming human mobility in a fundamental theological perspective and to recognize the integration of a phenomenon that challenges our national reality today.
\end{abstract}

Key words: migration, theology, mobility, christianity, epistemology.

Doctor en Teología Dogmática por la Pontificia Universidad de Salamanca, y actualmente Decano de la Facultad de Ciencias Religiosas de la Universidad Católica del Maule. Ha publicado "¿Cómo creer hoy en Dios? elementos para una introducción a la fe cristiana" (2008); "La fe como interpretación de la cultura" (2012); "John Henry Newman y la condición antropológica como fundamento para la teología de la credibilidad" (2015); "Ciencia positiva y fe religiosa: caminos hacia el conocimiento" (2016); “Hacia una verdadera religión” (2018). 


\section{INTRODUCCIÓN}

La migración, percibida equívocamente como algo nuevo en nuestro contexto local, nos abre a la pertinente pregunta sobre su naturaleza en atención a la ciudadanía. Del mismo modo el desafío al que nos llama como acontecimiento cultural, interpela nuestro quehacer nacional en distintos niveles y de diversas maneras. En efecto, la movilidad humana es un acontecimiento presente que ha puesto en la sensibilidad pública nacional una serie de inquietudes que, a su vez, han derivado en ciertas definciones normativas buscando regular aquello que exija de la intervención del Estado. Esta sensibilidad se ha visto aumentada desde ciertas perspectivas socio económicas y laborales, sobre todo a partir de la situación social que hemos visto florecer como país en el último tiempo. El dilema se presenta a través de ciertas decisiones administrativas de orden político, desde donde emergen convicciones sociales y culturales que tienden a relativizar y en otros casos, estigmatizar realidades migratorias no necesariamente ajustadas a la verdad, sino como producto del impacto que el fenómeno acarrea consigo ${ }^{1}$. Esta situación y sus derivadas hacen necesario considerar el fenómeno migratorio para ofrecer una perspectiva.

La mediación teórica desde la cual nos acercamos a reflexionar sobre el hecho, puede por supuesto, ser diversa y graduada en varios momentos que sería necesario reconocer desde su mérito. Importante aquí es el aporte epistemológico que puede ofrecer la sociología, la economía, la demografía, o la antropología cultural, por ejemplo. Pero la atención integral que requiere aproximar una visión más complexiva implica también una razonable profundización que ilumine las tensiones actuales desde otra epistemología, lo que incluye evidentemente el aporte que ofrece la teología de raigambre cristiana.

La situación no se enfrenta solo con una mirada técnica, económica o administrativa. Por lo mismo la insistencia de los Estados no puede reducirse a una serie de decisiones de fortificación de las fronteras, por ejemplo, como ha ocurrido dramáticamente en países occidentales, como el emblemático caso de tensión fronteriza entre Estados Unidos y México, donde se construyen muros y se sofistican las líneas de vigilancia (Nevins, 2002), a lo que se suma una serie de controles internos con el fin de reconocer a los indocumentados y facilitar, en el mejor de los casos, el retorno a sus países de origen. Más allá de este caso, hay que reconocer, ante todo,

\footnotetext{
1 Usamos de aquí en adelante el concepto "fenómeno" para referirnos a la migración sin ningún tipo de calificativo ni sesgo en particular, simplemente la utilización del concepto obedece al marco de situaciones o conesecuencias que entorno al hecho migratorio podemos referenciar, atender, o explicitar a lo largo del artículo.
} 
la necesidad de generar conciencia que, a un nivel más universal, los flujos migratorios han sufrido grandes transformaciones en la última década. Esto permite mirar con cierta naturalidad el hecho que los países, que tradicionalmente albergaban la mayor cantidad de inmigrantes, como ocurría hacia el 2005 con los Estados Unidos, Alemania, Rusia, y Ucrania, permitan hoy considerar la variable de proporcionalidad respecto de su población autóctona, destacando aquí por mucho, paises como: los Emiratos Árabes, Qatar, y Kuwait ${ }^{2}$.

Estas simples aproximaciones nos presentan ya un panorama diverso, pues, en síntesis, el desfío de la migración comprende muchas variables que redundan en la complejidad de una interpretación que va desde el registro mismo de los desplazamientos, hasta los impertaivos éticos que de aquí se generan, como el caso de los inmigrantes indocumentados que llegan a ser objeto de detención, abuso y expulsión. En una mirada más interna, el hecho que este tipo de prácticas se hagan cada vez más comunes y se acerquen geográficamente a nuestra realidad nacional habla de un giro y profundización del problema migratorio que se hace patente en medio de las políticas públicas y los desafíos sociales que hoy enfrentamos como país, llegando a ser una preocupación permanente en la diversificación de tareas que los gobiernos deben atender y regular. La cotidianidad de escenas que descubren los medios de prensa, en donde el fenómeno migratorio toma el protagonismo, no hace más que validar la dificultad, y proponernos el desafío ciudadano, ético y cristiano que la complejidad temática genera.

\section{MOVILIDAD HUMANA Y JUSTIFICACIÓN TEOLÓGICA}

En medio de la particularidad de situaciones migratorias brevemente descritas, la teología como ciencia de la fe entra para hacer reflexión de una realidad humana que interpela también a la propia confesionalidad, acogiendo la cita de Miguel de Unamuno (1983) que recoge las palabras de Publio Terencio, que en boca de Cremes decía en el año 165 antes de Cristo: "Soy humano, por lo tanto, nada de lo humano me es ajeno" [Homo sum, bumana nibil a me alienum puto] (Terencio, 1991: 39), así, la teología, como reflexión crítica del acontecimiento creyente que se ofrece en el plano de lo humano, no puede renunciar a atender tal o cual situación,

\footnotetext{
2 Según las Naciones Unidas, los migrantes representaban 25\% de la población total de Omán y Arabia Saudita, 62\% en Kuwait, 71\% en los Emiratos Árabes Unidos y 78\% en Qatar.
} 
menos aquellas que broten como paradigmáticas en humanidad ${ }^{3}$. En efecto, la teología estará siempre donde esté Dios, pues ella es su logos humano, y Dios en cuanto Dios se ha abreviado en una vida humana, tiene un nombre y un rostro (De Lubac, 1961).

En consecuencia, el cristianismo es y se comprende así mismo, no solo como un discurso dentro de la historia o un episodio de ella, de la naturaleza o la cultura, sino como consecuencia de una novedad de Dios que habla desde dentro de esa historia y sus acontecimientos, para ser reconocido como donación plena, autorevelada en Jesucristo y orientada al ser humano (González de Cardedal, 2013). Bajo esta premisa, el desafío epistemológico para atender al hecho migratorio no puede estar ajeno a las preocupaciones de la fe, como tampoco al desarrollo teológico que de aquí se derive.

Las consecuencias sociales y los fenómenos culturales, no son ajenos a la fe religiosa, nunca lo han sido, baste mirar - para no alejar el lente-, como un paradigmático ejemplo, la gran reacción teológica que despertó frente a la Ilustración, momento histórico, cultural y filosófico que interpelaba directamente el quehacer religioso y debilitaba en Occidente una cosmovisión cristiana, otrora entendida como robusta e inamobible, y que frente al devenir ilustrado palidecía en su propuesta. Es efectivamente en este periodo de la historia donde comienzan a emerger con mayor fuerza las “...tendencias de tipo deístico, es decir, un dios sólo natural, y sucesivamente, tomas de posición filosóficas y científicas de talante ateo o al menos agnóstico" (Valverde, 2003: 32). Frente a esto la teología reacciona con una nueva propuesta epistemológica, he aquí el porqué, en la dinámica que nos presenta el hecho migratorio, el discurso teológico en su dimensión epistemológica conciliar no puede estar ausente, no obstante, en la práctica se percibe ausente.

En efecto, análogamente a lo acontecido en el período ilustrado, la movilidad humana y los desplazamientos geográficos y demográficos en algunos casos, en cuanto desafío humano, obligan a la fe religiosa, en su dimensión teológica, iniciar la búsqueda de una comprensión de la realidad y de la migración, evidenciándola como parte y principio regulador de sus propias preocupaciones creyentes. Dios no es ajeno ni lejano, sino cercano a cada ser humano, mucho más íntimo que la propia intimidad ${ }^{4}$, al que se

3 Es la insistencia de Pedro Fernández en su apartado sobre la antropología teológica en Cordovilla et al. (2013: 173).

4 "...tu enim eras interior intimo meo et superior summo meo", Agustin de Hipona, confesiones III, 6, 11. Leibniz cita el texto del poeta latino Manilio, contemporáneo de Tiberio en su obra Astronomicas IV, 895: "Quid mirum noscere mundum/ si possumus homines? Quibus est et mundus in ipsis, / exemplumque Dei est sub imagine parva". El hombre un pequeño mundo y un pequeño dios; citado en González de Cardedal (2013: 24, nota 3). 
le puede encontrar siguiendo la dinámica de la conciencia (John Henry Newman), a través de la razón (Tomás de Aquino) y en el transcurrir de la historia (Hans Urs von Balthasar). He aquí una brevísima justificación del porqué lo teológico se ve exigido e interpelado por el fenómeno de la migración.

Con todo, la necesaria aproximación epistemológica al acontecimiento de la movilidad humana ha dado lugar a numerosos estudios que han afectado de distinto modo la comprensión del fenómeno en sí, como también el modo de acercarse a el. Esto ha permitido la introducción de nuevas epistemologías que han posibilitado diversificar las aproximaciones, buscando atender el problema en su complejidad. Del mismo modo la variedad de lecturas que frente al hecho se ofrecen y discuten, ha exigido que la enseñanza social cristiana proveniente del Magisterio eclesial, se haga cargo del tema, y proponga caminos que faciliten y muestren la particular sensibilidad que se ha tenido, y se debe tener. Por lo mismo el desafío se hace relevante y actual, en un escenario que ha tocado nuestra realidad país de modo explosivo en el último tiempo, y que, en consecuencia, necesita de una reflexión más consistente y teológicamente sostenible.

\section{MIGRACIÓN EN CHILE: BREVE MIRADA HISTÓRICA}

Hemos subrayado que el fenómeno de la migración ha estado presente de modo permanente en la historia humana, y nuestro país no ha sido una excepción a ello. De hecho, la migración se relaciona con nuestros propios orígenes históricos, incluso desde antes que tuvieramos historia patria. Hoy en día, dicho en términos muy simples, nuestro país cuenta aproximadamente con un $5 \%$ de su población que son migrantes, cifra que puede ser relevante, pero que en términos de impacto obedece principalmente al crecimiento explosivo que ha tenido en los últimos años. Ubicados en perspectiva histórica la comprensión del porcentaje de migrantes en nuestro país se relativiza, pues, aunque hablar de un $5 \%$ puede parecer hoy una alta cifra, según el Censo de 1907 el porcentaje de migrantes entonces en Chile ascendía a 4,1\%, lo que sugiere que hace más de cien años atrás la situación no era proporcionalmente muy distinta a la que hoy vivimos.

A lo anterior podríamos agregar, para tener una mirada mucho más integral, que los países que tienen mayor flujo migratorio, en Europa, por ejemplo, registran cifras por sobre el $10 \%$ y el $15 \%$ de población nacida en otros países, lo que indica que la movilidad humana en nuestro país, no es necesariamente una cuestión actual ni comparativamente relevante en términos de número. Mucho más potente puede ser el impacto que ha tenido en la población autóctona dado el aumento explosivo de población 
migrante que hoy podemos reconocer junto a la relevancia mediática que nos invade constantemente.

Las cifras, entonces, no redundan en un desequilibrio caótico en términos comparativos con nuestra propia historia. Más aún si nos comparásemos con otros países de la OCDE, por ejemplo, y bajo términos de porcentaje; en la suma, la migración en Chile resulta bastante menos significativa. Esto es lo que permite ratificar la idea que la preocupación por el fenómeno migratorio, siendo una realidad que hay que atender, no debiera exigir por parte de los gobiernos de turno una sobre exigencia preocupantemente mayor a la que han tenido otros paises, pues como vemos, en términos de número y proporcionalidad, nuestra situación país termina siendo cuantitativamente menos inquietante, que aquello que sostenemos en la coloquialidad de la información mediática, o dentro de nuestro entorno local.

Sin embargo, a pesar de las cifras y datos anteriormente señalados, no podemos anular, ni mucho menos negar las diversas realidades que por una complejidad de razones afloran entorno al fenómeno migratorio a nivel regional y nacional. El hecho exige atención y obliga a ofrecer una mirada que desde diversas perspectivas matice el impacto, pues es allí donde podemos reconocer hasta ahora el mayor desafío.

Aquí, la enseñanza social de la Iglesia ofrece una perspectiva epistemológica que tiende, en suma, a comprender la situación de un modo mucho más humano que técnico, o numérico-estadístico, y que se puede enfrentar desde dentro de la realidad migratoria misma, intentando explicar que esto no ocurre necesariamente por una volatilidad de situaciones de carácter subjetivo, sino que existen, en la generalidad de los casos, razones suficientes para migrar. Esta es la cuestión que permite no solo comprender el hecho sino, además, y he aquí lo importante, ofrecer una perspectiva más compleja, que nos lleve a atender esta realidad desde una mirada más humanista, y en consecuencia más cristiana. Pero ¿cómo es posible ofrecer esa mirada cristiana, teológica y humana al hecho migratorio? La respuesta a esta pregunta se presenta ante todo desde el devenir de la fe religiosa que hunde sus raíces en el acontecimiento de Israel, cuya plasmación histórica la podemos reconocer, al menos en un primer momento, en los antecedentes escriturísticos que la propia teología nos ofrece.

\section{MigRACIÓN Y SAgRADA ESCRITURA}

$\mathrm{Al}$ intentar atender a una lectura de la migración a partir de los datos que presenta la Palabra revelada, podemos evidenciar que el contendio de la Sagrada Escritura nos habla o sugiere la migración en sus principales momentos, unida a las características esenciales histórico-salvíficas que allí 
se encuentran. En este sentido el relato es amplio y definitivamente necesita de un recorrido y atención particular.

En efecto, ya el libro del Génesis nos sugiere el fenómeno de la migración a través de los textos que se nos presentan y que aluden a muchos individuos y grupos que se ven obligados, en razón de diversas circunstancias, a migrar. Caín es condenado a vagar por haber asesinado a su hermano Abel (Gn 4, 10-14). Un caso parecido es el de la torre de Babel donde la humanidad en rebeldía hacia Dios es llevada hacia una multiplicación de naciones (Gn 10-11). Taré sale de Ur y va hacia Harán, y Abram luego emigra de allí a Canaán (Gn 11, 31-12, 5). Abraham, Isaac y Jacob, salen de sus hogares por falta de alimentos para ubicarse en diferentes lugares: en Egipto (Gn 12, 42-46), el Neguev (Gn 20), y Filistea (Gn 26). Estas breves referencias que atienden al origen de los textos inspirados nos hacen posible identificar con cierta facilidad que la historia patriarcal de Israel está constituida esencialmente por el hecho migratorio que se reconoce con naturalidad en su principio y contexto más prístino (Gn 23, 4; Dt 26, 5), y que, bajo esta perspectiva, pueden reconocerse como un acontecimiento característico del origen de la fe judeo cristiana.

Detrás de los relatos mencionados, como parte constitutiva del corpus del Pentateuco, encontramos el concepto de extranjero o forastero, palabra con la cual generalmente podemos reconocer esta idea de aquel que viene de otra tierra. En la misma perspectiva se utiliza el concepto de extraño refieriéndose a aquel desconocido que forma parte de otra raíz o cultura, incluso se utiliza el concepto de peregrino, para hablar de quien viene o pertenece a otro lugar. Hablamos entonces, siguiendo en el marco veterotestamentario de las palabras; nekar y ger, y los dos adjetivos, nokrîy zar, reconociendo a través de ellos el significado del migrante en expresiones conceptuales distintas. En cualquier caso, queda clara la presencia de varios conceptos, con la que se hace referencia a lo que hoy podemos considerar como el que migra desde o hacia otras latitudes, y por lo mismo se nos sugieren distintas apreciaciones que existían respecto de quienes pertenecían o llegaban desde otras tierras o culturas a formar parte de Israel o a constituir la masa primigenia del pueblo elegido.

Los conceptos de Nekar y zar, por ejemplo, que ya citábamos, se refieren a algo o alguna persona que no es de Israel, y generalmente tienen una connotación negativa, distractora y amenazadora para Israel. Es el caso que podemos reconocer en Jos 24, 20; 1 R 11, 1-8; Esd 9-10; Ne 13, 23-27, por citar algunas referencias. En la misma línea se inscribe el término zar en el libro del Dt 32, 16, o el de los Pr 22, 14, e incluso en textos proféticos como el del primer Is 1,7 , citando algunos casos. 
En otros momentos de los escritos veterotestamentarios primitivos; los nekar estaban excluidos de ciertos festivales, como se expresa fielmente en el libro del Ex 12, 43, o en las referencias del libro de Rt 2, 10, y de igual manera en $1 \mathrm{R} 8,41.43$. Estas breves referencias bíblicas nos sugieren, en consecuencia, cierta distinción de aquellos migrantes que socialmente tenían menos rango ciudadano, si podemos actualizarlo así, respecto de aquellos que constituían la raigambre original del propio pueblo ${ }^{5}$. Un ejemplo claro de esto es lo que podemos destacar como afirmación explícita del libro del Dt 17,15, en donde aquellos que tenían categoría de extranjeros quedaban excluidos de ocupar dignidades de primer orden como la figura del rey. Lo que sugiere cierta connotación de exclusividad ya en la temprana narrativa de Israel. Con todo, no sería preciso, sin embargo, el reconocer que este tipo de personajes extranjeros y que se enuncian en la historia del pueblo elegido hayan tenido expresamente la idea de quedarse en medio de este pueblo, la referencia se asocia e identifica más bien con personas que llegaban de paso, o que, por actividades laborales como el negocio o comercio, solo transitaban a través de las tierras israelíes de modo pasajero.

Mención aparte tiene en esta mirada veterotestamentaria el concepto ger, que se repite alredededor de 90 veces en los relatos del Antiguo Testamento. Este concepto tiene la particularidad de estar vinculado a la raíz verbal gîr, que podemos traducir como residente, o pasar a ser residente de una determinada comunidad o localidad. Esto permite asociar de mejor manera el carácter de migrante a quienes se les aplicaba este calificativo en el antiguo Israel. Pues, en definitiva, hablamos aquí de una persona que viene a quedarse, a "residir", en medio de la localidad o la comunidad. Es el típico forastero que tiene un particular tratamiento en la doctrina y ley veterotestamentaria.

Con todo, podemos reconocer de este modo cierta tensión en la forma y comprensión del migrante que el antiguo Israel ofrece, pero cualquiera sea la aplicación del caso, nos permite adelantar que la movilidad humana es un acontecimiento natural en el devenir histórico del Antiguo Testamento, cuestión que se gesta y repite desde el origen de los mismos relatos y sucesos. En ocasiones esta movilidad, tomaba un giro distinto si el migrante o extranjero asumía características bienvenidas por la propia comunidad. Este es el caso de Rut que se casa con Booz tras la aceptación

5 Aunque no podemos desconocer que hubo muchos migrantes que en estos mismos contextos disfrutaron de un claro éxito: José adquirió prestigio en Egipto; Moisés fue criado en palacio (Ex 1-2); Daniel sirvió a varios reyes con distinción. Nehemías fue copero del rey persa Artajerjes $(\mathrm{Ne} 1,11)$. Sin embargo el hecho de ser extranjero simpre repercutió en su historiografía e itinerario misional, como el mismo Daniel que fue acusado por su fe y siendo víctima de burlas en un banquete (Dn 5-6). 
de los ancianos de la comunidad, luego de lo cual sus congéneres la reciben, valoran y aplauden (Rt 4, 11-15). El giro de esta extranjera es tan relevante que las líneas finales del libro revelan que Rut, a través de su hijo Obed, iba a formar parte de la genealogía de David (Rt 4, 18-22), lo que le permite luego, ya en el Nuevo testamento, ser incoporada en la extensa, pero a su vez privilegiada, genealogía de Jesús (Mt 1, 5).

En esta misma perspectiva y en complementación al caso de Rut, podemos citar otros tantos ejemplos cuyo protagonismo relevan una mirada más complexiva de la situación en los relatos veterotestamentarios. Es lo que ocurre con personajes determinantes en la historia de la salvación, como el caso de Jacob que huye de Esaú y se va a vivir a Jarán con Labán y su familia (Gn 27-31). El mismo José, importante personaje del final del libro del Génesis, y cuya historia comprende más de diez capítulos del libro, se ve expuesto por sus hermanos y traicionado por ellos, a la migración obligatoria, pues tras ser vendido como esclavo ( $\mathrm{Gn} 37$ ), radica su vida, tras un dramático relato, en las tierras egipcias. Es en estas mismas tierras, el lugar desde donde Moisés, ya décadas más tarde siguiendo un hilo histórico, escapa, para terminar viviendo y casándose, ya como extranjero, con una madianita. No es despreciable en este sentido que su hijo Gersón lleve en su raíz el concepto ger (Ex 2), cuestión que ya sugiere, precisamente su carácter de forastero en Madián.

Mirado en un sentido mucho más amplio, el mismo Israel, constituido ya como nación es sometido, en circunstancias históricas particulares al fenómeno migratorio, cuestión que es vivida sistemáticamente por el pueblo siglos más tarde, tanto en el exilio babilónico, como antes en el proceso que le significó la invasión en manos del imperio Asirio (2 R 17 y 24-25). Asi las cosas, el devenir de Israel está caracterizado por el hecho de la migración, atribuido en los relatos a relevantes personajes como Moisés, así como también en la mirada de vida común del pueblo en sus diversos episodios históricos. Incluso nos pueden inducir a un reconocimiento habitual que traspasa las categorías veterotestamentarias hacia aquellas que nos sugieren los relatos del Nuevo Testamento; 1 P 2, 11 afirma que todo creyente es extranjero en tierra extraña, ciudadanos de otro reino (Flp 3, $20 ; \mathrm{Hb} 13,14)$. Esta sorprendente afirmación viene a marcar una radical distancia con lo que se venía recogiendo en lenguaje veterotestamentario.

En efecto, los escritos de la nueva alianza permiten reconocer sendos conceptos que nos hablan de fenómenos migratorios, y del trato particular que se tiene con el migrante. Conceptos provenientes del griego como $x e-$ nos, paroikos y parepidemos, son utilizados para referirse a aquellos que vienen desde otras latitudes u otros lugares. El carácter positivo que pasa a tener para el discurso cristiano la figura del forastero, evidencia un cambio paradigmático en atención al discurso inclusivo de Jesús de Nazaret. Pues, la 
exclusión de la cual naturalmente padecía aquel que venía de otras latitudes, y su carácter de menor rango, limitado por las características propias derivadas del postexilio - como recordaba el Salmo 137 que expresa el enojo y la melancolía de aquellos que fueron llevados de Judá por Babilonia-, comienzan luego, en los relatos neotestamentarios, a tener ahora tras el mensaje de Cristo y la vocación universal a la salvación, una valoración mucho más inclusiva, cuestión que se materializa con cierta radicalidad, en el corpus paulino, donde ya no hay judío ni griego (Ga 3, 28).

La utilización en el Nuevo Testamento de conceptos como xenos, por ejemplo, que aparece cinco veces en Mt 25, 31-46, muestra una especie de ilativo entre la comprensión del Antiguo Testamento postexílico y el mensaje de Jesús. En efecto xenos y su raíz verbal xenizo tiene cierta ambivalencia en su definición y aplicación, pues en algunos casos se presenta con cierta connotación negativa, refiriéndose a aquello que es extraño y en ocasiones no muy bienvenido como le ocurre al apóstol Pablo, en el aréopago de Atenas (Hch 17, 20). En esa misma comprensión es identificable la utilización del concepto que ofrece la Carta a los Hebreos frente al cuidado de doctrinas extrañas que el documento advierte (Hb 13, 9). Por lo mismo decíamos que el concepto presenta una connotación problemática, que impide descubrir con cierta nitidez la aplicabilidad del mismo, aunque por supuesto existen varios otros momentos en donde los acentos no resultan tan excluyentes.

Un ejemplo de esto último es lo que se descubre en Ef 2, 19, referencia donde el concepto xenos aparece en paralelo al concepto paroikos para referirse a la relación entre Dios y su pueblo como itinerario de aquellos que progresivamente se van acercando a la fe, pasando a ubicarse transitivamente desde un estatus de extranjeros, para ser considerados conciudadanos. Con todo, termina siendo una aproximación mucho más positiva en la litaratura mateana la utilización del concepto xenos donde el extranjero se presenta desde una perspectiva positiva como agente de salvación: "Porque tuve hambre, y me disteis de comer; tuve sed, y me disteis de beber; fui forastero, y me recogisteis" (Mt 25, 35).

En cualquier caso es posible reconocer en los relatos bíblicos la presencia y vigencia del concepto que atiende a la realidad de aquellos que llegan desde otras latitudes, y que a imagen de una cierta pedagogía de Dios se va revelando progresivamente desde cierta carga negativa con ciertos matices de ambigüedad, hacia la positiva y definitiva reverencia que se tiene en los arbores del cristianismo primitivo, cuestión que el Magisterio eclesial ha recogido y valorado en sus principales documentos. En definitiva, el fenómeno de la migración no es un episodio que se entienda como un desafío exclusivamente presente, sino que, de alguna manera, ha sido una preocupación constante para la humanidad, que incluso tiene hondas 
raíces en la Historia de la salvación, en el cristianismo primitivo, como en la historia de la Iglesia, lo que permite acercar una aproximación a su estudio desde una epistemología que podríamos llamar, dado los principios que la fundamentan; teológico fundamental.

\section{LOS MIGRANTES EN EL MAGISTERIO MODERNO}

Dando un paso más en el desarrollo que venimos siguiendo, debemos destacar que el Compendio de Doctrina Social de la Iglesia (CDSI, en adelante), del Pontificio Consejo "Justicia y Paz" (2004), habla de la obligatoriedad que muchos sufren al tener que migrar a otras latitudes en razón del contexto que viven en sus propios países (CDSI 482). Lo mismo se puede evidenciar al hablar de las posibilidades y oportunidades de trabajo, que al no ser atendidas por sus propias naciones empujan a sus habitantes a dejar la tierra y emprender nuevos rumbos (CDSI 289), reconociendo positivamente en ello que el fenómeno de la migración, más que un obstáculo. puede ser un poderoso aliado para el desarrollo de los pueblos (CDSI 297). Sin embargo, esto no relativiza el hecho que el migrante, solo por la condición de serlo, pueda estar sujeto a determinados abusos sociales en los países a los que emigra. En esto, es la misma enseñanza social de la Iglesia, la que advierte sobre el riesgo de explotación que pueden sufrir los migrantes solo por el hecho de serlo (CDSI 298).

Desde una perspectiva histórica-magisterial, es posible reconocer que la movilidad humana ha sido un tema que ha preocupado a la Iglesia y la sistematización del Magisterio, solo considerando los últimos dos siglos, ratifican esta mirada. De hecho, existen registros formales ya desde mediados del siglo XIX, donde el clero solía acompañar a los grupos de migrantes que colonizaban nuevas tierras. En 1914 el Decreto Ethnografica studia [AAS 6 (1914), pp. 182-186] destacaba la responsabilidad de la Iglesia de asistir a los inmigrantes en los paises locales, incluso se invitaba a favorecer la preparación linguïstica, cultural y pastoral del clero indígena.

Asimismo, después de la promulgación del Código de Derecho Canónico de 1917, el Decreto Magni semper [AAS 9(1919), pp. 39-43] de 1918, confió a la Congregación Consistorial ${ }^{6}$ los procedimientos de autorización al clero para asistir a los migrantes, lo que da cuenta de la preocupación que existía entonces por atender a esta realidad, que se vislumbraba alojada en el quehacer pastoral de la Iglesia. En 1952 Pío XII elaboró una pastoral para asistir a los migrantes de donde emerge la Constitución apostólica

\footnotetext{
6 En 1912, después de la reforma de la Curia Romana realizada por San Pío X, fue creada la primera Oficina para los problemas de las migraciones en el seno de la Congregación Consistorial.
} 
Exsul Familia Nazarethana [AAS 44 (1952), pp. 649-704], considerada como la Carta Magna de la pastoral en favor de los migrantes ${ }^{7}$. En ella se solicita un esfuerzo para garantizar a los inmigrantes las mismas condiciones y atenciones pastorales de la que gozan otros cristianos autóctonos, incluso considerando algún tipo de adaptación a la pastoral si las exigencias lo proponen. La Exsul Familia, pasa a ser el documento oficial de la Santa Sede que abordaba de modo general y sistemático, considerando aspectos históricos y canónicos, el flujo migratorio y los desafíos de la movilidad.

El Concilio Vaticano II $(1975)^{8}$ ya había impulsado que en los planes pastorales se considerara la variable que implicaba, en ciertos casos, la atención que habría que tener hacia los migrantes cuya responsabilidad recaía principalmente en la figura del obispo (Ad gentes, n. 20). Lo que sugiere una explícita acogida y preocupación por ofrecer atención pastoral y humana a aquellos que se encontraban en situación de migración, cuestión que obligaba a las iglesias locales a generar pastoral con particular sensibilidad hacia el mundo migrante, en favor de la diversidad de situaciones que a partir de aquí emergían en los distintos contextos sociales, religiosos y culturales.

El Concilio atendía en su relato una permanente reflexión entorno a la realidad migratoria que se había materializado teológicamente a través de la Encíclica Pacem in terris de Juan XXIII (1963), que en su Primera parte, al tratar el tema del derecho de emigración y de inmigración, afirma: "Ha de respetarse íntegramente también el derecho de cada hombre a conservar o cambiar su residencia dentro de los límites geográficos del país; más aún, es necesario que le sea lícito, cuando lo aconsejen justos motivos, emigrar a otros países y fijar allí su residencia" (n. 25). Con esto el Papa Juan XXIII validaba las palabras de su predecesor Pío XII en su radiomensaje navideño del año 1952 [AAS 45 (1953), pp. 33-46]. Más adelante el Papa Pablo VI (1969) vuelve a relevar el hecho migratorio en el Motu Proprio Pastoralis Migratorum Cura, al igual que la Sagrada Congregación para los Obispos, en la Instrucción sobre la pastoral de los emigrantes Nemo est [AAS 61 (1969), pp. 614-643], que tiene como objeto principalmente el cuidado y atención pastoral que se le debe dar a los migrantes, relevando la preocupación manifestada en el Concilio Vaticano II, y ofreciendo con carácter de instructivo una serie de recomendaciones que se dirigían a ellos, insistiendo de modo particular en favorecer la atención

\footnotetext{
$7 \quad$ Véase los diversos comentarios de Bonet (1952); Governatori (1953); Tellechea (1953); Ferreto (1954) y Fus (1956), citados por Baura (2003: 54, n. 8).

8 Además de lo señalado aquí, el Concilio Vaticano II insiste en el derecho a la emigración (Gaudium et spes, n. 65), en la dignidad del emigrante (GS 66), como en la necesidad de superar las desigualdades que afectan al migrante (GS 63). El mismo Concilio reconoce también a la autoridad pública el derecho a reglamentar el flujo migratorio (GS 87).
} 
pastoral de aquellos que por diversas circunstancias se ven en esta condición de migrante. En este sentido la preocupación del Magisterio hacia el migrante se centra particularmente en su dignidad y su derecho a recibir la respectiva atención espiritual ${ }^{9}$. Respecto a esto último, el documento de Pablo VI detalla todas aquellas variables que la migración trae consigo, y la situación social no queda ausente incluyendo aquellas dimensiones, como la preocupación por el alojamiento, el trabajo y la enseñanza (MPC 61).

Todas estas características que la Iglesia enunciaba magisterialmente, se materializarán luego en el Código de Derecho Canónico, de 1983, que recomienda explícitamente al párroco una especial atención hacia quienes por diversas razones se encuentran lejos de su patria (c. 529, \$1), con el fin de ofrecerles una atención pastoral específica (c. 568). Incluso incorpora la erección de parroquias personales (c. 518) así como la figura de sujetos pastorales específicos, como el vicario episcopal (c. 476) y el capellán de los migrantes (c. 568). Todo esto entendido no como un coste para el país de destino o para la Iglesia en sí, sino todo lo contrario, como un aporte a ella. Años más tarde, el mismo Juan Pablo II (2001), insistía en su Mensaje para la celebración de la Jornada Mundial de la Paz, que muchas de las civilizaciones que se han desarrollado y enriquecido ha sido gracias a las aportaciones que en su momento ha realizado la inmigración, lo que garantiza la positiva percepción y valoración hacia el fenómeno en sí (véase también Juan Pablo II, 2001a: n. 55).

La constante preocupación de la Iglesia por la movilidad humana expresada a través de su Magisterio, va a recibir una nueva actualización con la publicación de la Instrucción Erga Migrantes Caritas Christi, publicada por el Pontificio Consejo para la Pastoral de los Emigrantes e Itinerantes (2004). En este documento se recoge lo que la reflexión magisterial ha formulado a lo largo del tiempo en un escenario de nuevos desafíos humanos y pastorales, lo que exigía de una nueva actualización. Más allá de los detalles introductorios que intenta recoger recapituladamente el documento, en su primera parte, sobresale el intento de considerar las distintas variables actuales que el hecho migratorio suscita, explicitando la necesidad de inculturación requerida y la atención peculiar y ecuménica que el fenómeno exige (nn. 34-36) ofreciendo para ello cierta estructura eclesial que sostenga la particular atención que se debe tener (nn. 70-74). En el

9 En 1970, el Papa Pablo VI instituyó la Comisión Pontificia para la Pastoral de las Migraciones y del Turismo que, en 1988, con la Constitución apostólica Pastor Bonus, se transformó en el Consejo Pontificio para la Pastoral de los Emigrantes e Itinerantes (véase https://www.vatican.va/roman_curia/pontifical_councils/migrants/index_sp.htm). 
contexto general se reconoce y ofrece un rol particular a los laicos y organizaciones seculares, cuyo servicio y misión se ven particularmente tocadas y estimuladas a trabajar por el mundo migrante a través de los diversos canales posibles (nn. 86-88). Este documento pasa a tener un lugar relevante en la pastoral migratoria actual porque viene a sugerir, recoger y enfatizar una sistematización necesaria para comprender la movilidad humana y la migración como una característica relevante de los pueblos en el mundo contemporáneo. Por su carácter de instrucción que involucra una serie de indicaciones de carácter normativo vienen a fortalecer y expresar una auténtica caridad evangélica que dialoga triconceptualmente con los conceptos teológico fundamentales expresados ya en Dei Verbum, orientando la acción pastoral hacia la caridad, lo que pone de manifiesto el sustento teológico que define el texto. A partir de la creciente población de origen árabe en Europa el documento señala:

Teniendo en cuenta especialmente los derechos humanos, aspiramos, por tanto, a que se produzca en nuestros hermanos y hermanas musulmanes una creciente toma de conciencia sobre el carácter imprescindible del ejercicio de las libertades fundamentales, de los derechos inviolables de la persona, de la igual dignidad de la mujer y del hombre, del principio democrático en el gobierno de la sociedad y de la correcta laicidad del Estado. Asimismo, habrá que llegar a una armonía entre la visión de fe y la justa autonomía de la creación (n. 66).

Esta referencia si bien orientada a la situación vivida en el viejo continente nos presenta ya, de modo suscinto la idea que la Instrucción intenta promover en su discurso, y a relevar como el mismo documento explicita la constante defensa y promoción de los derechos humanos fundamentales que se alinean con aquellos derechos propios para el reconocimiento positivo del mundo migrante.

El documento expresa muy positivamente y de modo destacado el valor de la migración viendo una clara empatía con la historia de la salvación (primera parte). En efecto, la Revelación cristiana ofrece sendas analogías con lo migratorio, y el pueblo de Israel en particular, toma como característica histórica fundante de su identidad, un carácter propio y común de una población migrante.

Del mismo modo el concepto de "signo de los tiempos" que tanto destacó la constitución Gaudium et spes, viene a reinterpretar el hecho migratorio, y a posibilitar en el concepto un llamado a lo teológico para releer el acontecimiento bajo el prisma de la fe manifestada en los acontecimientos de la historia. De ahí que se haga tan relevante el desarrollo de una pastoral que acoja las diversas realidades migratorias y que ofrezca en su 
seno un lugar especial para los migrantes (segunda parte) derivando en un llamado especial y articulado hacia los agentes pastorales (tercera parte) aludiendo a una impronta pastoral misionera (cuarta parte) que naturalize la solidaridad (nn. 39-43) y la comunión (nn. 37; 98-99).

Más específicamente el número 96 de la Instrucción expresa esta realidad, al hablar de las personas que se encuentran en éxodo y sobre las cuales la misma Iglesia invita a promover un constructivo diálogo y una fecunda relación de amistad e integración, valorando y reconociendo en otras culturas las semillas del verbo presente (n. 96). Lo que exige una permanente disposición al diálogo cultural, ecuménico e interreligioso (n. 100), en síntonía con la inculturación de la fe, contribuyendo así a justificar epistemológicamente una fundamentación teológica.

\section{TEOLOGÍA Y MIGRACIÓN}

Como hemos visto, la aproximación que se ha asumido desde el desarrollo magisterial eclesial es de larga data, y muestra una elaboración sistemática y sistémica para atender el desafío de la movilidad humana desde diversas perspectivas, situación exigida por la propia naturaleza eclesial. En efecto, el valor epistemológico que ofrece lo teológico y que brota de la Sagrada Escritura, como el aporte manifestado a lo largo de siglos de Tradición, y la sustentabilidad teológica ofrecida por el Magisterio, permite que se pueda reconocer desde lo teológico un vínculo consistente hacia la teología fundamental mediada por las propias bases epistemológicas del quehacer teológico, lo que incluye el propio carácter que ofrece a lo teológico la Constitución dogmátiva Dei Verbum en sus puntos fundamentales. Esto, evidentemente, no excluye la diversidad de miradas que frente al fenómeno podemos rconocer, sino que favorece una visión holística sustentada en los principios teológicos que sostienen la fe cristiana y que posibilitan una reflexión históricamente relevante de la situación.

En efecto, los distintos juicios con los que la movilidad humana se lee, nos evocaría hoy una pobreza interpretativa si es que quisiéramos sólo quedarnos de modo exclusivo con una mirada epistemológicamente parcial del problema en su conjunto. De aquí, que la relevancia ofrecida por la interpetación teológico-creyente del fenómeno de la migración interpele lo teológico y simpatice con lo apologético; la síntesis de la migración y teología fundamental cobra relevancia de esta manera.

En este sentido no resulta baladí que el lugar donde se desarrolla la primera teología cristiana en sus cimientos fundamentales sea precisamente el Areópago de Atenas, allí donde estuvieron y pasaron diversas voces, diversas oratorias, diversos pensamientos, diversas culturas. Es a este lugar donde llega el apóstol Pablo para anunciar al dios desconocido 
(Hch 17, 22-24), aquí donde la religión, la política y la filosofía se encontraban naturalmente tras una impronta multicultural que trascendía. En este sentido el apóstol abre la matriz que sustenta el cristianismo, evidenciando que también en este lugar multicultural, la fe en Jesucristo encontraba un espacio. Esto permea la razón religiosa de comprender que esta multiculturalidad manifestada a través del hecho migratorio proporciona un lugar teológico que se transforma en palabra de verdad y buena nueva de salvación, favoreciendo el imbrincado teológico fundamental que el hecho manifiesta.

Por el contrario, la distorsión que puede producirse al tener una mirada poco complexiva de la realidad que no incorpore otras epistemologías como la teológico fundamental, que proyecta positivamente el hecho migratorio desde sus origenes en razón de los componentes ya señalados, pueden derivar en una serie de lecturas simplistas muchas veces originadas por visiones ideológicas o puramente técnicas.

Un ejemplo de esto es la parcialidad del juicio que se materializa en una percepción de la Migración que tiene en cuenta solo parte de la totalidad de variables. Quienes migran, en efecto, son los ciudadanos más jóvenes, lo que se traduce en una pérdida de masa productiva en los países de origen, pero a su vez, en un fortalecimiento en niveles semejantes en los países de destino. Esta conclusión positiva para los paises receptores de migración, abre paso a lo que se conoce comúnmente como el brain drain, en razón de la generación de un nuevo capital cultural o científico que se introduce gratuitamente en los paises receptores de migrantes, que se justifica aún más al no haber mayor inversión de estos mismos paises en los grupos que reciben. Este acontecimiento, positivo en principio para los paises de destino trastoca la mirada de la migración pudiendo reconocer desde el punto de vista de las políticas de estado una percepeción positiva del fenómeno. Sin embargo, la percepción social se resiste a tomar conciencia de este hecho para quedarse con la idea de que la comunidad migrante es mucho más un problema que un beneficio para el país que les recibe. De no incorporar una epistemología más integrada e integradora de la situación, que considere otra forma de leer la realidad total del fenómeno se pueden instalar ideas injustas y con variables éticas luego muy complejas de reorientar. Es aquí donde la teología fundamental tiene su propio desafío.

\section{CONCLUSIÓN}

La situación de la migración tiene hondas raíces en la literatura bíblica y en el Magisterio eclesial mediado por la Tradición. Es posible reconocer con claridad en los relatos bíblicos la presencia y vigencia del concepto 
que atiende a la realidad de aquellos que llegan desde otras latitudes, y que a imagen de una cierta pedagogía de Dios se va revelando progresivamente desde una carga negativa con ciertos matices de ambigüedad, hacia la positiva reverencia que se le otorga en los arbores del cristianismo primitivo.

Así, la clara acogida que el hecho migratorio ofrece, da cuenta de la relevancia que para las líneas del Nuevo Testamento se solicitan. Los efectos de las migraciones son, en este sentido, una especie de signo visible (sacramentum) de la universal llamada a la salvación que caracterizaba a la Iglesia primitiva y debe caracterizar por naturaleza hoy a la comunidad creyente, fruto de su propia teología. La situación actual en Chile desafía, en consecuencia, el rol teológico y su aplicación pastoral en el reconocimiento de carencias sociales que no se pueden sostener. El marco teológico fundamental que ve favorecer una mirada del hecho migratorio en sus propias raíces, posibilita robustecer el análisis y no puede palidecer frente a las exigencias que por su propia naturaleza su fundamentación declara.

Todo este horizonte de sentido bíblico, Magisterial, y Tradición viva, sustenta el desarrollo de una epistemología ausente en el ethos social del fenómeno, y como hemos visto, también necesaria, en el camino que Erga Migrantes Carita Cristi declara en su contenido y materializa en sus fundamentos, lo que deriva en una perspectiva teológica fundamental sostenida en las fuentes de revelación que no se puede dejar de atender y anunciar.

\section{REFERENCIAS}

Baura, E. (2003). Movimientos migratorios y derechos de los fieles en la Iglesia. IUS CANONICUM, 43(85), 51-86.

Bonet, M. (1952). Reseña jurídico-canónica. Revista Española de Derecho Canónico, 7(19), 801-803.

Concilio Vaticano II (1975). Constituciones. Decretos. Declaraciones. Madrid: Biblioteca de Autores Cristianos.

Cordovilla, A. et al. (2013). La lógica de la fe. Manual de teología dogmática. Madrid: Universidad Pontificia Comillas.

De Lubac, H. (1961). Exégèse Mediévale. Les quatre sens de l'Écriture. Paris: Verbum abbreviatum.

De Unamuno, M. (1983). Del sentimiento trágico de la vida. La agonía del cristianismo. Madrid: Akal.

Ferreto, G. (1954). Sua Santità Pio XII provvido padre degli esuli e sapiente ordinatore dell'assistenza spirituale agli emigranti. Apollinaris, (27), 323-355.

Fus, E.A. (1956). Priest emigrants under the Constitution "Exsul Familia". The Jurist, (16), 359-386.

González de Cardedal, O. (2013). Dios en la ciudad. Salamanca: Sígueme. 
Governatori, L. (1953). Commentarium in Const. Ap. "Exsul Familia”. Apollinaris, (26), 155-174.

Juan XXIII (1963). Enciclica Pacem in Terris sobre la paz entre todos los pueblos que ha de fundarse en la verdad, la justicia, el amor y la libertad. 11 de abril. Disponible en http://www.vatican.va/content/john-xxiii/es/encyclicals/documents/hf_j-xxiii_enc_11041963_pacem.html

Juan Pablo II (2001). Mensaje para la celebración de la XXXIV Jornada Mundial de la Paz, 1 de enero. Disponible en http://www.vatican.va/content/johnpaul-ii/es/messages/peace/documents/hf_jp-ii_mes_20001208_xxxivworld-day-for-peace.html

Juan Pablo II (2001a). Carta Apostólica Novo millennio ineunte. 12 de enero. Disponible en http://www.vatican.va/content/john-paul-ii/es/apost_letters/2001/documents/hf_jp-ii_apl_20010106_novo-millennio-ineunte.html

Nevins, J. (2002). Operation Gatekeeper. The Rise of the 'Illegal Alien' and the Making of the U.S.-Mexico Boundary. New York: Routledge.

Pablo VI (1969). Carta Apostólica en forma de Motu Proprio Pastoralis Migratorum Cura, 15 de agosto. Disponible en https://www.vatican.va/content/paulvi/la/motu_proprio/documents/hf_p-vi_motu-proprio_19690815_pastoralis-migratorum-cura.html

Pontificio Consejo "Justicia y Paz" (2004). Compendio de la Doctrina Social de la Iglesia. Disponible en http://www.vatican.va/roman_curia/pontifical_councils/justpeace/documents/rc_pc_justpeace_doc_20060526_compendiodott-soc_sp.html

Pontificio Consejo para la Pastoral de los Emigrantes e Itinerantes (2004). Instrucción Erga Migrantes Caritas Christi (La caridad de Cristo hacia los emigrantes). 3 de mayo. Disponible en http://www.vatican.va/roman_curia/pontifical_councils/migrants/documents/rc_pc_migrants_doc_20040514_erga-migrantes-caritas-christi_sp.html

Tellechea, J. I. (1953). La cura pastoral de los emigrantes. Comentario a la Constitución Apostólica «Exsul Familia» de $1^{\circ}$ de agosto de 1952. Revista Española de Derecho Canónico, 8(23), 539-578.

Terencio (1991). Comedias. El Heautontimorumenos. Formión (Vol. II). Salamanca: Consejo Superior de Investigaciones Científicas.

Valverde, C. (2003). Génesis, estructura y crisis de la modernidad. Madrid: Biblioteca de Autores Cristianos. 